Special Issue -

MHGC Proceeding 2020

\title{
Symptom. Toxic story
}

\author{
Tatiana Grischuk
}

Association of Psychotherapists and Psychoanalysts of Ukraine

\section{Case Study Keywords}

Mental health, mental feelings, neurotic symptom, pathological response, mental pathology.

Address for correspondence:

Tatiana Grishchuk, Tatiana Grishchuk

Psychologist, psychoanalyst, sexologist. Association of Psychotherapists and Psychoanalysts of Ukraine.e-mail: grischukt29@gmail.com

Submitted for publication: 17

May 2020

This work is licensed under a Creative Commons Attribution-

NonCommercial 4.0 International License (CC BY-NC 4.0).

Received: 17 May 2020

(c) (i) (3)

Accepted for publication: 16

October 2020

(C) Copyright: Grishchuk, 2020

Licensee NDSAN (MFC- Coordinator of the NDSAN), Italy

DOl: http://doi.org/10.32437/mhgci.v4i2.91

\section{Introduction}

Such symptoms as hard, complex, bodily or mental feelings, that turn our everyday life into a hell, at first, lead us to a doctor, and then - to a psychotherapist. A sick man is keen to get rid of a symptom. A doctor prescribes medication, that is ought to eliminate a symptom. A psychotherapist searches for a reason of the problem that needs to be removed.

There is such an idea that a neurotic symptom, in particular, an anxiety - is a pathological (spare or extra) response of a body. It is generally believed that such anxiety doesn't have some real, objective reasons and that it is the result of a nervous system disorder, or some disruption of a cognitive sphere etc.

Meanwhile, it is known that in the majority of cases, medical examinations of anxious people show that they don't have any organic damages, including nervous system. It often happens that patients even wish doctors have found at least any pathology and have begun its treatment. And yet - there is no pathology. All examinations indicate a high level of functionality of a body and great performance of the brain's work. Doctors throw their hands up, as they can't cure healthy people. One of my clients told me her story of such medical examinations (which l'll tell you with her permission). She said that it was more than 10 years ago. So, when she told her doctor all of her symptoms - he seemed very interested in it. He placed a helmet with electrodes on her head and wore some special glasses, when, according to her words, he created some kind of stressful situation for her brain, as she was seeing some flashings of bright pictures in her eyes. She said that he had been bothered with her for quite a long time, and at the end of it he had told her that her brain had been performing the best results in all respects. He noted that he'd rarely got patients with such great health indicators. My client asked the doctor how rare that was. And he answered: "one client in two or three months." At that moment my client didn't know whether to be relieved, flattered or sad. But since then, when someone told her that anxiety was a certain sign of mental problems, or problems with the nervous system, or with a body in general, she answered that people who had anxiety usually had already got all the required medical examinations sufficiently, and gave them the advice to go through medical screening by themselves before saying something like that.

Therefore, we see a paradoxical situation, when some experts point to a neurotic anxiety as if it is a kind of pathology, in other words - some result of a nervous system disorder. Other specialists in the same situation talk about cognitive impairments. And some, after all the examinations, are ready to send such patients into space 
Special Issue -

MHGC Proceeding 2020

\section{Main text}

I don't agree with the statement that any neurotic anxiety that happens is excessive and unfounded. It often happens that there is objective, specific and real causes for appearance of anxiety conditions. And these causes require solutions. And it's not about some organic damages of the brain or nervous system. The precondition that may give a rise to anxiety disorder is the development of such a life story that at some stage becomes too toxic - when, on the one hand, a person interacts with the outside world in a way that destroys his or her personality, and, on the other hand, this person uses repression and accepts such situation as common and normal. Repression - is an essential condition for the development of a neurotic symptom. Sigmund Freud was the first who pointed this out.

Repression is such a defense mechanism that helps people separate themselves from some unpleasant feelings of discomfort (pain) while having (external or internal) irritations. It is the situation when, despite the presence of irritations and painful feelings, a person, however, doesn't feel any of it and is not aware of them in his or her conscious mind. Repression creates the situation of so-called emotional anesthesia. As a result, a displacement takes place, so a body starts to signal about the existing toxic life situation via a symptom.

Anxiety disorder is usually an appropriate response (symptom) of a healthy body to an unhealthy life situation, which is seen by a person as normal. And it's common when such a person is surrounded by others (close people), who tend to benefit from such situation, and so they actively maintain this state of affairs, whether it is conscious for them or not.

At the beginning of a psychotherapy almost all clients insist that everything is good in their lives, even great, as it is like in everyone else's life. They say that they have only one problem, which is that goddamn symptom. So they focus all of their attention on that symptom. They are not interested in all the other aspects of their life, and they show their irritation when it comes to talking about it. People want to get rid of it, whatever it takes, but they often tend to keep their lives the way that it was. In such cases a psychotherapist is dealing with the resistance of clients, trying to turn their attention from a symptom to their everyday situation that includes their way of thinking, interactions with themselves and with others and with the external world in order to have the opportunity to see the real problem, to live it through, to rethink and to change the story of their lives.

For better understanding about how it works I want to tell you three allegorical tales.

The name of the first tale is "A frog in boiling water".

There is one scientific anecdote and an assumption (however, it is noted that such experiments were held in 19 century), that if we put a frog in a pot with warm water and start to slowly heat the water, then this frog get used to the temperature rise and stays in a hot water, the frog doesn't fight the situation, slowly begins to lose its energy and at the last moment it couldn't find enough strength and energy to get out of that pot. But if we throw a frog abruptly in hot water - it jumps out very quickly.

It is likely that a frog, that is seating in boiling water, will have some responses of the body (symptoms). For example, the temperature of its body will rise, the same as the color of it, etc., that is an absolutely normal body response to the existing situation.

But let us keep fantasizing further. Imagine a cartoon where such a frog is the magical cartoon hero, that comes to some magical cartoon doctor, shows its skin, that has changed the color, to the doctor, and asks to change the situation by removing this unpleasant symptom. So the doctor prescribes some medication to return the natural green color of the frog's skin back. The frog gets back in its hot water. For some period of time this medication helps. But then, after a while, the frog's body gets over the situation, and the redness of the frog's skin gets back. And the magical cartoon doctor states that the resistance of the body to this medication has increased, and each time prescribes some more and more strong drugs.

In this example with the frog it is perfectly clear that the true solution of the problem requires the reduction of the water temperature in that pot. We could propose that magical cartoon frog to think and try to realize that: 1) the water in that pot is hot, and that is the reason why the skin is red; 2) the frog got used to this situation and that is why it is so unnoticeably for this frog; 3 ) if the temperature of the water in the pot still stay so hot, without any temperature drop, then all the medication works only temporarily; 4) if we lower the temperature in that pot - the redness disappears on its own, automatically and without any medication. 
Special Issue -

MHGC Proceeding 2020

Also this cartoon frog, that will go after the doctor to some cartoon physiotherapist, will face the necessity to give itself some answers for such questions as: 1) What is going on? Who has put this frog in that pot? Who is raising the temperature progressively? Who needs it? And what is the purpose or benefit for this person in that? Who benefits? 2) Why did the frog get into the pot? What are the benefits in it for the frog? Or why did the frog agree to that? 3) What does the frog lose when it gets out of this pot? What are the consequences of it for the frog? What does the frog have to face? What are the possible difficulties on the way? Who would be against the changes? With whom the frog may confront? 4) Is the frog ready to take control over its own pot in its own hands and start to regulate the temperature of the water by itself, so to make this temperature comfortable for itself? Is this frog ready to influence by itself on its own living space, to take the responsibility for it to itself?

The example "A frog in boiling water" is often used as a metaphorical portrayal of the inability of people to respond (or fight back) to significant changes that slowly happen in their lives. Also this tale shows that a body, while trying to adjust to unfavorable living conditions, will react with a symptom. And it is very important to understand this symptom.

Symptom - is the response of a body, it's a way a body adjusts to some unfriendly environment.

Symptom, on the one hand, informs about the existence of a problem, and from the other hand - tries to regulate this problem, at least in some way (like, to remove or reduce), at the level on which it can do it. The process is similar to those when, for example, in a body, while it suffers from some infectious disease, the temperature rises. Thus, on the one hand, the temperature informs about the existence of some infection. On the other hand, the temperature increase creates in a body the situation that is damaging for the infection. So, it would be good to think about in what way does an anxiety symptom help a body that is surrounded by some toxic life situation. And this is a good topic for another article.

Here I want to emphasize that all the attempts to remove a symptom without a removal of a problem, without changing the everyday life story, may lead to strengthening of the symptom in the body. Even though the removal of a symptom without elimination of its cause has shown success, it only means that the situation was changed into the condition of asymptomatic existence of a problem. And it is, in its essence, a worse situation. For example, it can cause an occurrence of cancer.

The tale "A frog in boiling water" is about the tendency of people to treat a symptom, instead of seeing their real problems, as its cause, and trying to solve it. People don't want to see their problems, but it doesn't mean that the problem doesn't exist. The problem does exist and it continues to destroy a person, unnoticeably for him or her.

A person with panic disorder could show us anxiety that is out of control (fear, panic), which, by its essence, seems to exist without any logical reason. Meanwhile the body of such a person could be in such processes that are similar to those that occur in the conditions of some real dangers, when the instinct for self-preservation is triggered and an automatic response of a body to fight or flight implements for its full potential. We can see or feel signs of this response, for example, in cases when some person tries to avoid some real or imaginary danger via attempts to escape (the feeling of fear), or tries to handle the situation by some attempts to fight (the feeling of anger).

As I mentioned before, many doctors believe that such fear is pathological, as there is no real reason for such intense anxiety. They may see the cause of the problem in worrisome temper, so they try to remove specifically anxiety rather than help such patients to understand specific reason of their anxiety, they use special psychotherapeutic methods that are designed to help clients to develop logical thinking, so it must help them to realize the groundlessness of their anxiety.

In my point of view, such anxiety often has specific, real reasons, when this response of a body, fight or flight, is absolutely appropriate, but not excessive or pathological. Inadequacy, in fact, is in the unconsciousness, but not in the reactions of a body.

For a better understanding of the role of anxiety in some toxic environment, that isn't realized, I want to tell you another allegorical tale called "The wolf and the hare".

Let us imagine that two cages were brought together in one room. The wolf was inside one cage and the hare was in another. The cages were divided by some kind of curtain that makes it impossible for them to see each other. At this point a question arises whether the animals react to each other in some way in such a situation, or not? I think that yes, they will. Since there are a lot of other receptors that participate in the receiving 
Special Issue -

MHGC Proceeding 2020

and processing of the sensory information. As well as sight and hearing, we have of course a range of other senses. For example, animals have a strong sense of smell.

It is well known that people, along with verbal methods of communicating information, like language and speaking, also have other means of transmitting information - non-verbal, such as tone of voice, intonation, look, gestures, body language, facial expressions etc., that gives us the opportunity to receive additional information from each other. The lie detector works by using this principle: due to detecting non-verbal signals, it distinguishes the level of the accuracy of information that is transmitted.

It is assumed, that about $30 \%$ of information, that we receive from the environment, comes through words, vision, hearing, touches etc. This is the information that we are aware of in our consciousness, so we could consciously (logically) use it to be guided by. And approximately $70 \%$ of everyday information about the reality around us we receive nonverbally, and this information in the majority of cases could remain in us without any recognition. It is the situation when we've already known something, and we even have already started to respond to it via our body, but we still don't know logically and consciously that we know it. We can observe the responses of our own body without understanding what are the reasons for such responses.

We can recognize this unconscious information through certain pictures, associations, dreams, or with the help of psychoanalysis. Psychoanalysis is a great tool that can help to recognize the information from the unconscious mind, so that it can be logically processed further on, in other words, a person then receives the opportunity to indicate the real problems and to make right decisions.

But let us return to the tale where the hare and the wolf stay in one room and don't see each other, and, maybe, don't hear, though - feel. These feelings (in other words - non-verbal information that the hare receives) activate a certain response in the hare's body. And it reacts properly and adequately to the situation, for instance, the body starts to produce adrenaline and runs the response "fight or flight". So the hare starts to behave accordingly and we could see the following symptoms: the hare is running around his cage, fussing, having some tremor and an increased heart rate, etc..

And now let us imagine this tale in some cartoon. The hare stays in its house, and the wolf wanders about this house. But the hare doesn't see the wolf. Though the body of the hare gives some appropriate responses. And then that cartoon hare goes to a cartoon doctor and asks that doctor to give it some pill from its tremor and the increased heart rate. And in general asks to treat in some way this incomprehensible, confusing, totally unreasonable severe anxiety.

If we try to replace the situation from this fairytale to a life story, we could see that it fits well to the script of interdependent relationships, where there are a couple "a victim and an aggressor", and where such common for our traditional families' occurrences as a domestic family violence, psychological and physical abuse take place. Only in 2019 a law was passed that follows the European norms and gives a legislative definition of such concepts as psychological domestic abuse, sexual abuse, physical abuse, bullying, that criminalizes all of these occurrences, establishes the punishment and directly points to people that could be a potential abuser. Among them are: a husband towards his wife, parents towards their children, a wife towards her husband, a superior towards a subordinate, a teacher towards his or her students, children towards each other etc..

When it comes to recognition of something as unacceptable, it seems more easy to put to that category such occurrences as physical and sexual abuse, as we could see here some obvious events. For example, beating or sexual harassment. Our society is ready to respond to these incidents in more or less adequate way, and to recognize them as a crime. But it is harder to deal with the recognition of psychological abuse as an offence. Psychological abuse in our families is common. Psychological abuse occurs through such situations, when one person, while using different psychological manipulations, such as violation of psychological borders, imposition of feeling of guilty or shame, etc., force another person to give up his or her needs and desires, and so in such a way make this person live another's life. Such actions have an extremely negative effect on the mental health of these people, just as much as physical abuse. It can destroy a person from the inside, ruin self-esteem and a feeling of self-worth, create the situation of absolute dependence such victim from an abuser, including financial dependence etc.. It often happens that psychological abuse takes place against the backdrop of demonstrations of care and love.

So you've got this story about the wolf and the hare, that are right next to each other, and the 
Special Issue -

MHGC Proceeding 2020

shield between two of them is a repression - a psychological defense mechanism, when a person turns a blind eye to such offences, that take place in his or her own life and towards him or her. And this person considers this as normal, doesn't realize, doesn't have a resource to realize, that it is a crime. Most importantly - doesn't feel anything, as a repression takes place. But a body responds in a right way - from a certain point of the existence of such a toxic situation the response "fight or flight" is launched in a body at full, in other words - the fear and anxiety with the associated symptoms.

The third allegorical tale I called "Defective suit", which I read in the book of Clarissa Pinkola Estés with the name "Running With the Wolves".

"Once one man came to a tailor and started to try on a suit. When he was standing in front of a mirror, he saw that the costume had uneven edges.

Don't worry, - said the tailor. - If you hold the short edge of the suit by your left hand nobody notices it.

But then the man saw that a lapel of a jacket folded up a little bit.

It's nothing. You only need to turn your head and to nail it by your chin.

The customer obeyed, but when he put on trousers, he saw that they were pulling.

All right, so just hold your trousers like this by your right hand - and everything will be fine, the tailor comforts him.

The client agreed with him and took the suit.

The next day he put on his new suit and went for a walk, while doing everything exactly in the way that the tailor told him to. He waddled in a park, while holding the lapel by his chin, and holding the short edge of the suit by his left hand, and holding his trousers by his right hand. Two old men, who were playing checkers, left the game and started to watch him.

Oh, God! - said one of them. - Look at that poor cripple.

Oh, yes - the limp - is a disaster. But I'm wondering, where did he get such a nice suit?"

Clarissa wrote: "The commentary of the second old man reflects the common response of the society to a woman, who built a great reputation for herself, but turned into a cripple, while trying to save it. "Yes, she is a cripple, but look how great her life is and how lovely she looks." When the "skin" that we put on ourselves towards society is small, we become cripples, but try to hide it. While fading away, we try to waddle perky, so everyone could see that we are doing really well, everything is great, everything is fine".
As for me, this tale is also about the process of forming a symptom in a situation when one person tries very hard to match to another one, whether it is a husband, a wife or parents. It's about a situation when such a person always tries to support the other one, while giving up his or her own needs and causing oneself harm in such a way by feeling a tension every day, that becomes an inner normality. And so this person doesn't give oneself a possibility to relax, to be herself (or himself), to be spontaneous, free. As a result, in this situation the person, who was supported, looks perfect from the outside, but those who tried to match, arises some visible defect, like a limp - a symptom. And so this person lives like a cripple, under everyday stress and tension, trying to handle it, while sacrificing herself (or himself) and trying to maintain this situation, so not to lose the general picture of a beautiful family and to avoid shame.

The tailor, who made this defective suit and tells how to wear the suit properly, in order to keep things going as they are going, often is a mother who raised a problematic child and then tells another person how to deal with her child in the right way. It is the situation when a mother-in-law tells her daughter-in-law how to treat her son properly. In other words, how to support him, when to keep silent, to handle, how to fit in, so that her problematic son and this relationship in general looks perfect. Or vice versa, when a mother-in-law tells her son-in-law how to support her problematic daughter, how to fit in etc..

When, for example, a woman acts like this in her marriage and with her husband, with these excessive efforts to fit in - then after a while everybody will talk like: "Look at this lovely man: he lives with his sick wife, and their family seems perfect!". But when such a woman becomes brave enough to relax and to just let the whole thing go, everybody will see that the relationship in her marriage isn't perfect, and it is the other one who has problems.

Each time when someone tries excessively to match up to another one, while turning oneself in some kind of a cripple, - he or she, on the one hand, supports the comfort of that person, to whom he or she tries to match up, and on the other hand - such a situation always arises in that person such conditions as a continuous tension, anxiety, fear to act spontaneously. A symptom - is like a visible defect, that shows itself through the body (and may look like some kind of injury). It is the result of a hidden inner prison.

As a result of evolution, a pain tells us about a problem that is needed to be solved. When we 
Special Issue -

repress our pain we can't see our needs and our problems at full. And then a body starts to talk to us via a symptom.

Psychotherapy aims for providing a movement from a symptom to a resumption of sensitivity to feelings, a resumption of the ability to feel your psychological pain, so you can realize your own toxic story.

In this perspective another fairy-tale looks interesting to analyze - it is Andersen's fairytale "Princess and the Pea". In the tale a prince wanted to find a princess to marry. There was one requirement for women candidates, so the prince could select her among commoner - high level of sensitivity, as the real princess would feel a pea through the mountain of mattresses, and so she could have the ability to feel discomfort, to be in a good contact with her body, to tell about her discomfort without such feeling as shame and guilt, and to refuse that discomfort, so to have the readiness to solve her problems and to demand from others the respect for her needs.

It is common for our culture that the expression "a princess on a pea" very often uses for a negative meaning. So people who are in good contact with their body and who can demand comfort for themselves are often called capricious. At the same time the heroes who are ready to suffer and to tolerate their pain, who are able to repress (stop to feel) their pain represents a good example to be followed in our society.

So, we may see the next algorithm in cases of various anxiety disorders:

1. the existence of some toxic situation that brings some danger to a person. And we need not to be confused: a danger exists not for a body, but for a personality. A toxic live situation as well as having a panic attack is not a threat for the health of a body (that is what medical examinations show), and vice versa - it's like every day intensive sport training, that could be good for your health only to some degree. A toxic situation destroys a person as a personality, who longs for one self's expression;

2. the existence of such a defense mechanism as repression - it's a life with closed eyes, in pink glasses, when there is inability (or the absence of the desire) to see its own toxic story;

3.the presence of a symptom - a healthy response of a body "fight or flight" to some toxic situation;

4. displacement - it's replacement of the attention from the situation to a symptom, when a person starts to see and search for the problem in some other place, not where it really is. A symptom takes as some spare, pathological reaction that we need to get rid of. The readiness to fight the symptom arises, and that is the goal of such methods of therapy as pharmacological therapy, CBT and many others;

5. the absence of adequate actions that are directed towards the change of a toxic situation itself. The absence of the readiness to show aggression when it comes to protect its space.

All of it is a mechanism of formation of primary anxiety and preparation for launch of secondary anxiety. A complete anxiety disorder is the interaction between a primary and a secondary anxiety.

\section{Conflict of interest}

Author declares that she has no conflict of interests 